\title{
Pseudoaneurisma gigante de la aorta ascendente fistulizado a la aurícula derecha
}

\author{
Giant ascending aortic pseudoaneurysm fistulized into right atrium \\ Delicia Gentille-Lorente* \\ Servicio de Cardiología, Hospital de Tortosa Verge de la Cinta. Tortosa, Tarragona, España
}

Varón de 69 años, con historia de reemplazo valvular mecánico mitroaórtico y de la aorta ascendente por una prótesis tubular dos años atrás, que ingresó por insuficiencia cardiaca biventricular (predominantemente derecha). En el ecocardiograma destacó la existencia de un ventrículo derecho (VD) severamente dilatado y disfuncionante, prótesis con gradientes elevados e hipertensión pulmonar severa; el estudio transesofágico (ETE) descartó la trombosis protésica. Mediante tomografía computarizada se detectó la existencia de un pseudoaneurisma de la aorta ascendente (PAA) de 92×95 mm de diámetros que rodeaba el injerto aórtico

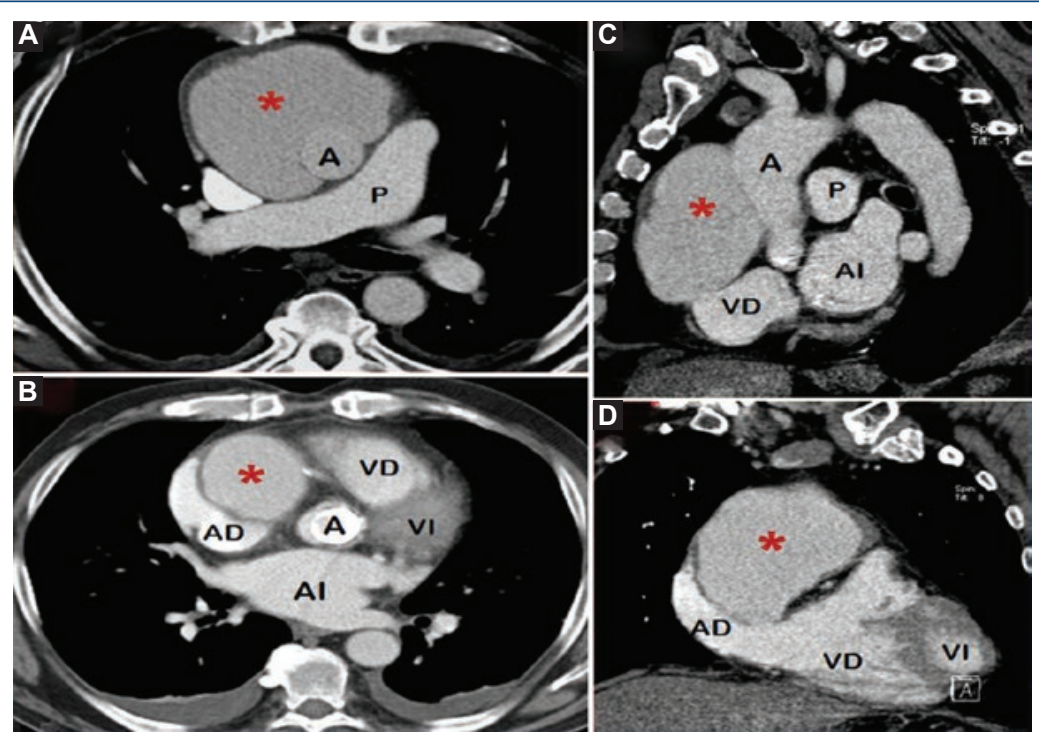

Figura 1. Imágenes de tomografía computarizada. A y B: cortes axiales donde se observa el gran pseudoaneurisma (*) formado entorno a la prótesis tubular aórtica y la compresión severa que ejerce sobre la AD. C y D: mismas alteraciones pero observadas en los cortes sagitales realizados a esos mismos niveles.

A: aorta; AD: aurícula derecha; Al: aurícula izquierda; VD: ventrículo derecho; VI: ventrículo izquierdo; P: arteria pulmonar.

\section{Correspondencia:}

*Delicia Gentille-Lorente

E-mail: dgentille.ebre.ics@gencat.cat
Disponible en internet: 30-01-2020 Arch Cardiol Mex. 2020;90(1):88-89

www.archivoscardiologia.com

2604-7063/C 2019 Instituto Nacional de Cardiología Ignacio Chávez. Publicado por Permanyer. Este es un artículo open access bajo la licencia CC BY-NC-ND (http://creativecommons.org/licenses/by-nc-nd/4.0/). 


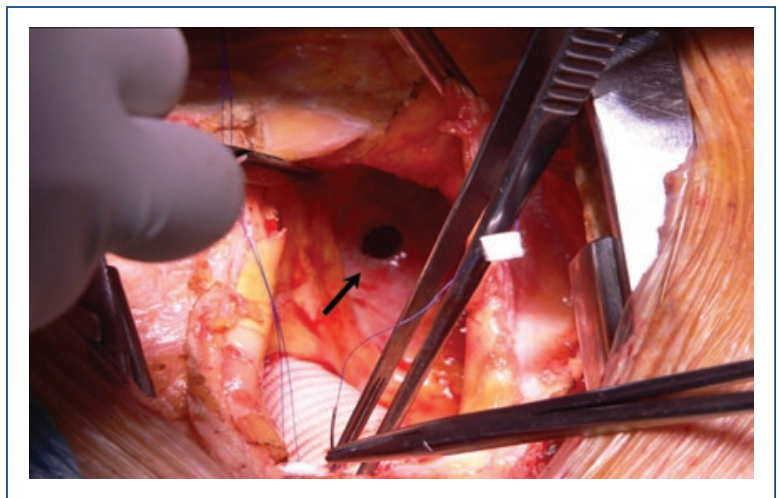

Figura 2. Imagen de la cirugía: apertura del pseudoaneurisma aórtico. Tras el drenaje del seudoaneurisma se observa la prótesis tubular aórtica, no epitelizada, y al fondo, en su pared, el orificio (flecha) de la fístula a la aurícula derecha.

y comprimía la aurícula derecha (AD) (Fig. $\left.1\left[{ }^{\star}\right]\right)$; una segunda ETE demostró, además, la existencia de una fístula desde el PAA a la AD. El paciente fue intervenido: se cerró la fístula (Fig. 2 [flecha]), y la prótesis valvular aórtica junto con el injerto tubular aórtico (que no estaba epitelizado y presentaba roturas en sus anastomosis proximal y distal como orígenes del PAA), se sustituyeron por una prótesis aórtica tubular valvulada.

EI PAA constituye una patología muy rara; su incidencia, tras una intervención aórtica, es $<1 \%$ y se ve favorecida por las infecciones perioperatorias ${ }^{1}$. Generalmente su origen está en los puntos de aortotomía, anastomosis o líneas de sutura (de prótesis o injertos de derivación aortocoronaria), o en puntos de punción, canulación o clampaje aórticos. La clínica varía según su localización, tamaño y compresión sobre estructuras adyacentes; sin embargo, resulta excepcional su presentación como disfunción cardiaca derecha (síndrome de vena cava superior, obstrucción de la entrada del $\mathrm{VD}$, o fístula a arteria pulmonar, $\mathrm{AD} \circ \mathrm{VD})^{2,3}$.

\section{Financiamiento}

\section{Ninguno.}

\section{Conflicto de intereses}

$$
\text { Ninguno. }
$$

\section{Responsabilidades éticas}

Protección de personas y animales. Los autores declaran que para esta investigación no se han realizado experimentos en seres humanos ni en animales.

Confidencialidad de los datos. Los autores declaran que han seguido los protocolos de su centro de trabajo sobre la publicación de datos de pacientes.

Derecho a la privacidad y consentimiento informado. Los autores han obtenido el consentimiento informado de los pacientes y/o sujetos referidos en el artículo. Este documento obra en poder del autor de correspondencia.

\section{Bibliografía}

1. Rodrigues A, Santos I, Paduá Ch, Souza Y. Pseudoaneurysm of ascending aorta. J Gen Emerg Med. 2017;2(5):29.

2. Kar P, Gopinath R, Padmaja D, Kumar RV. Complex pseudoaneurysm of ascending aorta: Unusual cause of right heart dysfunction-implications to the anesthesiologist. J Anaesthesiol Clin Pharmacol. 2015;31(2):246-9.

3. Howard E, Velasco C, Roullard Ch, Rafael A. Aorto-right atrial fistula after bentall repair. Proc (Bayl Univ Med Cent). 2017;30(3):301-2. 